\title{
Alelopatia de Brachiaria brizantha cv. Marandu em bactérias promotoras do crescimento vegetal
}

\author{
Allelopathy of Brachiaria brizantha cv. Marandu in plant growth-promoting bacteria \\ Alelopatía de Brachiaria brizantha cv. Marandu en bacterias promotoras del crecimiento vegetal
}

Recebido: 28/01/2022 | Revisado: 02/02/2022 | Aceito: 05/02/2022 | Publicado: 10/02/2022

\author{
Carla Neves Toledo \\ ORCID: https://orcid.org/0000-0002-1966-7070 \\ Universidade José do Rosário Vellano, Brasil \\ E-mail: carlantoledo@yahoo.com.br \\ Elisa Rocha \\ ORCID: https://orcid.org/0000-0003-3210-0287 \\ Universidade José do Rosário Vellano, Brasil \\ E-mail: elisa.rocha@aluno.unifenas.br \\ Bruna Aparecida Araújo \\ ORCID: https://orcid.org/0000-0001-8270-0104 \\ Universidade José do Rosário Vellano, Brasil \\ E-mail: bruna.araujo@aluno.unifenas.br \\ Nhayandra Christina Dias Silva \\ ORCID: https://orcid.org/0000-0003-1804-8312 \\ Universidade José do Rosário Vellano, Brasil \\ nhayandra_dias@yahoo.com.br \\ Adauton Vilela Rezende \\ ORCID: http://orcid.org/0000-0001-8515-484X \\ Universidade José do Rosário Vellano, Brasil \\ E-mail: adauton.rezende@unifenas.br \\ Ligiane Aparecida Florentino \\ ORCID: https://orcid.org/0000-0001-9092-3017 \\ Universidade José do Rosário Vellano, Brasil \\ E-mail: ligiane.florentino@unifenas.br
}

\begin{abstract}
Resumo
Objetivou-se com este estudo verificar a influência de compostos alelopáticos liberados por Brachiaria brizantha cv. Marandu na tolerância de bactérias promotoras do crescimento vegetal (BPCV). Foram obtidos extratos da parte aérea e raiz de $B$. brizantha nas concentrações de 12,5; 25,0; 50,0 e 75,0\% e avaliado o efeito no crescimento de 10 estirpes de BPCV utilizando as metodologias de perfuração em ágar e diluição seriada. O experimento foi instalado em delineamento inteiramente casualizado (DIC) em esquema fatorial, 10 × 5 × 2 com 4 repetições, sendo 10 estirpes bacterianas, 5 constituindo as quatro diferentes concentrações e um tratamento controle (sem extrato) e 2 extratos de compostos alelopáticos, parte aérea e radicular, de $B$. brizantha. Foi verificado inibição pelo extrato radicular na concentração de $75 \%$ para as estirpes UNIFENAS 100-01; 100-13; 100-39; 100-02 e 100-94 pelo método da perfuração do ágar. As demais estirpes cresceram normalmente no meio de cultura em todas as concentrações. De acordo com os dados obtidos foi possível observar que os extratos alelopático de $B$. brizantha podem interferir no crescimento de estirpes de BPCV, podendo comprometer a eficiência destas quando utilizadas como inoculantes.

Palavras-chave: Compostos metabolismo secundário; Fatores limitantes ao crescimento bacteriano; Sustentabilidade produção animal.
\end{abstract}

\begin{abstract}
The objective of this study was to verify the influence of allelopathic compounds released by Brachiaria brizantha cv. Marandu on the tolerance of plant growth-promoting bacteria (PGPB). Extracts of shoots and roots of B. brizantha were obtained at concentrations of $12.5 ; 25.0 ; 50.0$ and $75.0 \%$ and evaluated the effect on the growth of 10 PGPB strains using agar drilling and serial dilution methodologies. The experiment was installed in a completely randomized design (CRD) in a factorial scheme, $10 \times 5 \times 2$ with 4 replications, 10 bacterial strains, 5 constituting the four different concentrations and a control treatment (without extract) and 2 extracts of allelopathic compounds, shoot and root, of $B$. brizantha. Inhibition was verified by the root extract at a concentration of $75 \%$ for the UNIFENAS 100-01 strains; $100-13 ; 100-39 ; 100-02$ and 100-94 by the agar perforation method. The other strains grew normally in the culture medium at all concentrations. According to the data obtained, it was possible to observe that allelopathic
\end{abstract}


extracts of B. brizantha may interfere with the growth of PGPB strains, which may compromise their efficiency when used as inoculants.

Keywords: Secondary metabolism compounds; Limiting factors to bacterial growth; Sustainability animal production.

\begin{abstract}
Resumen
El objetivo de este estudio fue verificar la influencia de los compuestos alelopáticos liberados por Brachiaria brizantha cv. Marandu sobre la tolerancia de las bacterias promotoras del crecimiento vegetal (BPCV). Se obtuvieron extractos de brotes y raíces de $B$. brizantha a concentraciones de 12,$5 ; 25,0 ; 50,0$ y 75,0\% y evaluó el efecto sobre el crecimiento de 10 cepas de BPCV utilizando metodologías de perforación en agar y dilución en serie. El experimento se instaló en un diseño completamente aleatorizado (DCA) en esquema factorial, $10 \times 5 \times 2$ con 4 repeticiones, 10 cepas bacterianas, 5 constituyendo las cuatro diferentes concentraciones y un tratamiento control (sin extracto) y 2 extractos de compuestos alelopáticos, brote y raíz, de B. brizantha. La inhibición fue verificada por el extracto de raíz a una concentración de 75\% para las cepas UNIFENAS 100-01; 100-13; 100-39; 100-02 y 100-94 por el método de perforación de agar. Las otras cepas crecieron normalmente en el medio de cultivo en todas las concentraciones. De acuerdo con los datos obtenidos, fue posible observar que los extractos alelopáticos de $B$. brizantha pueden interferir en el crecimiento de las cepas de BPCV, lo que puede comprometer su eficiencia cuando se utilizan como inoculantes. Palabras clave: Compuestos del metabolismo secundario; Factores limitantes del crecimiento bacteriano; Sustentabilidad producción animal.
\end{abstract}

\title{
1. Introdução
}

Os microrganismos desempenham funções cruciais para a qualidade do solo e nutrição vegetal. Nas últimas décadas a pesquisa tem atuado de forma intensiva na identificação e seleção de estirpes bacterianas conhecidas por bactérias promotoras do crescimento vegetal (BPCV) para aplicação no campo, reduzindo de forma efetiva o uso de insumos agrícolas e proporcionando maior sustentabilidade aos agroecossistemas.

As BPCV são capazes de fixar nitrogênio atmosférico $\left(\mathrm{N}_{2}\right)$, solubilizar fósforo e potássio, produzir AIA e controlar fitopatógenos (Florentino et al., 2017A; Florentino et al., 2017B; Dias et al., 2019; Terra et al., 2019). No entanto, a sobrevivência e a eficiência para desempenhar esses processos no solo depende de diversos fatores, como a fertilidade, condições climáticas e a espécie vegetal (Moreira et al., 2006). Em relação à este último parâmetro, tem-se que as plantas influenciam diretamente o ambiente rizosférico, podendo favorecer ou não a sobrevivência de determinados grupos microbianos (Mandon et al., 2021). Dentre os diversos compostos liberados pelas plantas, pode-se destacar os compostos alelopáticos ou aleloquímicos (Lorenzo et al., 2013; Polyak et al., 2019).

A alelopatia é definida como a produção de compostos do metabolismo secundário por plantas, algas e microrganismos que podem interferir no desenvolvimento de outra espécie (IAS, 1996; Almeida-Bezerra et al., 2020). Diversos estudos tem sido desenvolvidos visando identificar os compostos metabólicos liberados pelas plantas e suas espécies alvo (Silva et al., 2018; Silva et al., 2021). No entanto, essas pesquisas tem-se limitado principalmente às espécies vegetais, necessitando ampliar para os grupos de microrganismos do solo que desempenham processos importantes do ponto de vista econômico e ambiental, como as BPCV.

Segundo Martins et al. (2006), os compostos liberados por Brachiaria brizantha cv. Marandu interferiram negativamente nos processos germinativos de Panicum maximum cv. Tanzânia, Sida rhombifolia e Peschiera fuchsiaefolia. Toledo et al. (2019) discorrem sobre a influência desses compostos produzidos por B. brizantha sobre as bactérias diazotróficas associativas, as quais se estabelecem na rizosfera e nos tecidos vegetais. Segundo esses autores, a alelopatia pode ser um dos motivos da ausência de resposta à inoculação em muitos estudos envolvendo esta gramínea forrageira.

Baseado nessas informações e considerando a importância das BPCV para a sustentabilidade da produção animal, objetivou-se com esse estudo avaliar a influência de compostos alelopáticos liberados por Brachiaria brizantha cv. Marandu na tolerância de bactérias promotoras do crescimento vegetal. 


\section{Metodologia}

\section{Obtenção do extrato}

O experimento foi conduzido no Laboratório de Microbiologia do Solo e no setor de Experimentação da Universidade José do Rosário Vellano (UNIFENAS). Para obtenção do extrato contendo os compostos alelopáticos, foram coletadas a parte aérea e raízes de plantas de Brachiaria brizantha cv. Marandu cultivadas no campo agrostológico do setor de Ciências Agrárias da UNIFENAS. Foi realizada a coleta de amostra de solo, camada de 0-20 cm na área cultivada com B. brizantha, apresentando os seguintes resultados: $\mathrm{pH}\left(\mathrm{H}_{2} \mathrm{O}\right)=5,8 ; \mathrm{P}-$ Mehlich $=8,0 \mathrm{mg} \mathrm{dm}^{-3} ; \mathrm{K}^{+}=133 \mathrm{mg} \mathrm{dm}^{-3} ; \mathrm{Ca}^{2+}=2,0 \mathrm{cmol}_{\mathrm{c}} \mathrm{dm}^{-3}$; $\mathrm{Mg}^{2+}=1,0 \mathrm{cmol}_{\mathrm{c}} \mathrm{dm}^{-3} ; \mathrm{Al}^{3+}=0,2 \mathrm{cmol}_{\mathrm{c}} \mathrm{dm}^{-3} ; \mathrm{H}+\mathrm{Al}=3,4 \mathrm{cmol}_{\mathrm{c}} \mathrm{dm}^{-3} ;$ Soma de bases $(\mathrm{SB})=3,3 \mathrm{cmol}_{\mathrm{c}} \mathrm{dm}^{-3} ; \mathrm{CTC}_{\text {potencial }}=$ $6,7 \mathrm{cmol}_{\mathrm{c}} \mathrm{dm}^{-3}$; Saturação por bases (V\%) = 49; Saturação por alumínio $(\mathrm{m} \%)=6$; Matéria orgânica (M.O.) $=20 \mathrm{~g} \mathrm{~kg}^{-1}$.

O material vegetal (parte aérea e raiz) foi seco em estufa de circulação de ar forçada, a $60^{\circ} \mathrm{C}$, por $72 \mathrm{~h}$, e em seguida para obtenção do extrato, foi seguida a metodologia descrita por Hagemann et al. (2010), em que o material foi submerso em álcool etílico 95\%, na proporção de 1:5 (p/v), homogeneizado e mantido em temperatura ambiente por 72 horas. Posteriormente o material foi filtrado e o resíduo (parte aérea ou raiz) foi novamente diluído com o solvente álcool etílico 95\% na proporção 1:5, e deixado em repouso por mais 72 horas. Esse processo foi repetido até a obtenção de um extrato puro.

O composto filtrado resultante e todas as extrações foram reunidos e concentrados em rotaevaporador de pressão reduzida, em temperatura média de $50^{\circ} \mathrm{C}$. Posteriormente, o extrato bruto concentrado foi solubilizado em Dimetilssulfóxido (DMSO) a $1 \%$ e água destilada para obtenção das diferentes concentrações de: $12,5 \% ; 25,0 \% ; 50,0 \%$ e $75 \%$ conforme metodologia descrita por Paula et al. (2016).

\section{Estirpes bacterianas}

Foram utilizadas dez estirpes bacterianas pertencentes à coleção do Laboratório de Microbiologia do Solo da UNIFENAS, identificadas como UNIFENAS 100-01; 100-13; 100-39, 100-02, 100-78, 100-26, 100-71, 100-40, 100-69 e 10094. Essas estirpes foram isoladas em meios de cultura semissólidos e semi-seletivos em áreas de pastagens no Sul de Minas Gerais (Dias et al., 2019) e possuem comprovada capacidade de atuar como promotoras do crescimento vegetal. Na Tabela 1 estão apresentadas a identificação das estirpes, o meio de origem utilizado no isolamento e as principais funções realizadas para a promoção do crescimento vegetal, assinaladas pela letra x, seguidas das citações. 
Tabela 1. Identificação, meio utilizado para isolamento das bactérias e capacidade de realizar a fixação biológica de nitrogênio $(\mathrm{FBN})$, solubilizar fósforo $(\mathrm{P})$, potássio $(\mathrm{K})$ e produzir ácido 3-indol acético (AIA) pelas estirpes bacterianas utilizadas no estudo.

Promoção do crescimento vegetal

Estirpes $\quad$ Meio de isolamento

FBN Solubilização de P Solubilização de K $\quad$ Produção de AIA

\begin{tabular}{|c|c|c|c|c|c|}
\hline UNIFENAS 100-01 & $\mathrm{JNFb}$ & & $x^{3}$ & $\mathrm{x}^{5,7}$ & $x^{6}$ \\
\hline UNIFENAS 100-02 & JMV & $x^{1,2}$ & $x^{3}$ & & $x^{3}$ \\
\hline UNIFENAS 100-13 & $\mathrm{JNFb}$ & $x^{1}$ & $\mathrm{x}^{3,4}$ & $\mathrm{x}^{5,7}$ & $x^{3}$ \\
\hline UNIFENAS 100-26 & LGI & $x^{1}$ & & $\mathrm{x}^{5,7}$ & \\
\hline UNIFENAS 100-39 & $\mathrm{JNFb}$ & & $\mathrm{x}^{3,4}$ & $\mathrm{x}^{5,7}$ & $\mathrm{x}^{3,6}$ \\
\hline UNIFENAS 100-40 & $\mathrm{JNFb}$ & $x^{1,2}$ & $\mathrm{x}^{3}$ & $\mathrm{x}^{5,7}$ & $\mathrm{x}^{3,6}$ \\
\hline UNIFENAS 100-69 & LGI & $x^{1,2}$ & $x^{3}$ & & $x^{3}$ \\
\hline UNIFENAS 100-71 & JMV & $\mathrm{x}^{1,2}$ & $x^{3}$ & & $x^{3}$ \\
\hline UNIFENAS 100-78 & LGI & $x^{1,2}$ & $x^{3}$ & & $x^{3}$ \\
\hline UNIFENAS 100-94 & JMV & $x^{1}$ & $x^{3}$ & $\mathrm{x}^{5,8}$ & $x^{6}$ \\
\hline
\end{tabular}

${ }^{1}$ Silva et al. (2019); ${ }^{2}$ Dias et al. (2019), ${ }^{3}$ Terra et al. (2019); ${ }^{4}$ Paredes Filho et al. (2020A); ${ }^{5}$ Florentino et al. (2017A); ${ }^{6}$ Florentino et al. (2017B); ${ }^{7}$ Paredes Filho et al. (2020B). Fonte: Autores (2022).

As estirpes bacterianas foram cultivadas em meio FAM para formação de colônia isolada e confirmação da pureza, sendo posteriormente, repicadas para meio FAM líquido, cultivadas por três dias, a fim de para atingir a fase log de crescimento, aproximadamente $10^{8} \mathrm{UFCmL}^{-1}$.

\section{Influência do extrato de Brachiaria brizantha no crescimento das estirpes bacterianas}

Para avaliar a ocorrência de efeito inibitório no desenvolvimento das estirpes bacterianas, foram utilizadas duas técnicas, sendo a primeira pelo método de perfuração em ágar e a segunda por diluição seriada. Em ambas foi utilizado o meio de cultura FAM, a pH 6,8 e contendo azul de bromotimol como indicador.

Na primeira técnica, a perfuração do meio de cultura foi seguida conforme a metodologia descrita por Ostrosky et al. (2008). Inicialmente procedeu-se a inoculação com a suspensão das diferentes estirpes bacterianas cultivadas até a fase logarítmica. Após, foram realizados os poços no meio de cultura, utilizando-se cilindros de 8 mm de diâmetro e em seguida, nos poços, procedeu-se a aplicação dos extratos oriundos da parte aérea e raiz de $B$. brizantha nas diferentes concentrações mencionadas anteriormente. Como controle foi utilizada a solução de DMSO a 1\%. As placas foram incubadas por 72 horas e após, foi avaliado a formação de halos de inibição.

Para a técnica de diluição seriada, inicialmente realizou-se a mistura de $500 \mu \mathrm{L}$ do inóculo bacteriano cultivado no meio líquido FAM até a fase logarítmica e $500 \mu \mathrm{L}$ do extrato de $B$. brizantha em suas diferentes concentrações, totalizando-se $1 \mathrm{~mL}$ de amostra, o qual foi adicionado a tubos contendo $9 \mathrm{~mL}$ de solução salina $(\mathrm{NaCl})$ 0,55\% esterilizada, obtendo-se a diluição $10^{-}$ 
${ }^{1}$. Foram realizadas as sucessivas diluições até a diluição $10^{-9}$. Como controle foi utilizada a solução de DMSO a $1 \%$. As placas foram incubadas por 72 horas e após esse período procedeu-se a contagem das UFC.

Ambos os experimentos foram instalados em delineamento inteiramente casualizado (DIC), em esquema fatorial $10 \mathrm{x} 5$ x 2, sendo 10 estirpes bacterianas, 5 constituindo as quatro diferentes concentrações e um tratamento controle (sem extrato) e 2 extratos de compostos alelopáticos da parte aérea e radicular de B. brizantha. Foram utilizadas quatro repetições.

\section{Resultados e Discussão}

\section{Influência do extrato de Brachiaria brizantha no crescimento das estirpes bacterianas}

Em relação ao crescimento das estirpes bacterianas quando dispostas em contato com os extratos de B. brizantha, foi observado a formação de halo de 2 mm para os tratamentos inoculados com as estirpes UNIFENAS 100-01; 100-02, 100-13; 100-39 e 100-94 na maior concentração, 75\%, do extrato da raiz de B. brizantha, pelo método de perfuração em ágar. Esses resultados demonstram que os compostos alelopáticos produzidos por esta planta pode interferir na sobrevivência dessas estirpes bacterianas, que desempenham importantes processos, como a fixação biológica de nitrogênio atmosférico ( $\left.\mathrm{N}_{2}\right)$, solubilização de fósforo e potássio e produção de AIA, conforme demonstrado na tabela 1.

Já pela técnica de diluição seriada não foi verificado efeito dos compostos alelopáticos, uma vez que todas as estirpes apresentaram crescimento em todas as diluições, diante de todas as concentrações de extratos extraídos da parte aérea e raiz de B. brizantha.

A influência dos compostos alelopáticos sobre os microrganismos do solo tem sido relatada em alguns estudos. Lorenzo et al. (2013) observaram que a alelopatia produzida por Acacia dealbata reduz significativamente a riqueza e diversidade de bactérias no solo. No entanto, esses autores observaram também que o efeito negativo sobre a comunidade microbiana é dependente do tipo e conservação do ecossistema, sendo que em solos de floresta mista, contendo maior diversidade de espécies, a comunidade microbiana mostrou-se insensível aos compostos alelopáticos produzidos por $A$. dealbata

A ocorrência de efeito negativo ou não dos compostos alelopáticos sobre os microrganismos do solo relatado por Lorenzo et al. (2013), pode ser explicado, por Almeida (1988), os quais relatam sobre a ocorrência de degradação dos metabólitos secundários de origem vegetal pelos microrganismos do solo. Podendo-se assim, estabelecer uma relação direta entre o manejo do solo e o efeito da alelopatia, indicando a importância do equilíbrio biológico no solo.

O efeito da alelopatia sobre os microrganismos do solo também é relatado no trabalho de Witter et al. (2021), em que verificaram o efeito negativo dos aleloquímicos liberados pela canola (Brassica napus L.) sobre bactérias diazotróficas. Kong et al. (2008) verificaram que mudas de arroz produz compostos alelopáticos e que estes reduziram significativamente a comunidade microbiana.

Considerando os resultados obtidos, verifica-se que a $B$. brizantha cv. Marandu possui compostos alelopáticos que podem interferir negativamente na sobrevivência de bactérias promotoras do crescimento vegetal. Com isso, observa-se a necessidade de condução de novas pesquisas considerando esse tema, visto que testes de alelopatia podem ser considerados nos ensaios de seleção de estirpes bacterianas promotoras do crescimento vegetal.

\section{Conclusão}

Brachiaria brizantha cv. Marandu produz compostos alelopáticos que interferem no crescimento de bactérias promotoras do crescimento vegetal.

Estudos posteriores devem ser realizados em campo visando identificar o efeito dos compostos alelopáticos sobre bactérias diazotróficas no campo. 


\section{Agradecimentos}

Os autores agradecem o apoio financeiro das agências CAPES e FAPEMIG.

\section{Referências}

Almeida, L. F. R., Portella, R. O., Bufalo, J., Marques, M. O. M., Facanali, R. \& Frei, F. (2016). Non-Oxygenated sesquiterpenes in the essential oil of Copaifera langsdorffii desf. Increase during the day in the dry season. Plos One, 11 (2), 1-12.

Almeida-Bezerra, J. W., Viana, J. W. M., Silva, V. B., Costa, A. R., Costa, M. H. N., Santos, M. A. F., Macedo, G. F., Lima, E. E., Torquato, I. H. S., Rodrigues, J. L. G., Teixeira, P. H. R., Oliveira, J. P. C., Batista, A. P., Sousa, F. V. A., Pereira, C. M. \& Correia, D. B. (2020). Allelopathy? I don’t know! I've never seen! I only hear about it! Research, Society and Development, 9 (12), e19391210873.

Dias, M. S., Florentino, L. A., Rabêlo, F. H. S., Rezende, A. V., Souza, F. R. C. \& Borgo, L. (2019). Características morfológicas, produtivas e bromatológicas do capim-xaraés: adubação nitrogenada em cobertura versus inoculação com bactérias diazotróficas. Ciência Animal Brasileira, 20 (1), 1-12.

Florentino, L. A., Rezende, A. V., Miranda, C. C. B., Mesquita, A. C., Mantovani, J. R. \& Bianchini, H. C. (2017A). Potassium solubilization in phonolite rock by diazotrophic bacteria. Comunicata Scientiae, 8 (1), 17-23.

Florentino, L. A., Silva, A. B., Landgraf, P. R. C. \& Souza, F. R. C. (2017B). Inoculação de bactérias produtoras de ácido 3-indol acético em plantas de alface (Lactuca sativa L.). Revista Colombiana de Ciência Hortícolas, 11 (1), 89-96.

Hagemann, T. R., Benin, G., Lemes, C., Marchese, J. A., Martin, T. N., Pagliosa, E. S \& Beche, E. (2010). Potencial alelopático de extratos aquosos foliares de aveia sobre azevém e amendoim-bravo. Bragantia, 69 (3), 509-518.

IAS-International Allelopathy Society. (1996). Disponível em: < https://allelopathy-society.osupytheas.fr/ >. Acesso em: 08 jul de 2021 Kong, C. H., Wang, P., Zhao, H., Xu, X. H. \& Zhu, Y. D. (2008). Impact of allelochemical exuded from allelopathic rice on soil microbial community. Soil Biology and Biochemistry, 40 (1), 1862-1869.

Lorenzo, P., Pereira, C. S. \& Rodrigue-Echeverria, S. (2013). Differential impact on soil microbes of allelopathic compounds released by the invasive Acacia dealbata. Soil Biology and Biochemistry, 57 (1), 156-163.

Mandon, K., Nazaret, F., Farajzadeh, D., Alloing, G. \& Frendo, P. (2021). Redox Regulation in Diazotrophic Bacteria in Interaction with Plants. Antioxidants, $10(6), 1-18$.

Moreira, F. M. S. \& Siqueira, J. O. (2006). Microbiologia e Bioquímica do Solo. 2ª Edição. Editora UFLA. 729 p.

Ostrosky, E. A., Mizumoto, M. K., Lima, M. E. L., Kaneco, T. M., Nishikawa, S. O. \& Freitas, B. R. (2008). Métodos para a avaliação da atividade antimicrobiana e determinação da concentração mínima inibitória (CIM) de plantas medicinais. Revista Brasileira de Farmacognosia, 18 (2), $301-307$.

Paredes Filho, M. V., Silva, A. B. \& Florentino, L. A. (2020A). Solubilization of Araxá natural phosphate and decomposition of plant residues by bacterial isolates. Ciência e Agrotecnologia, 44: e008420.

Paredes Filho, M. V., Mesquita, A. C., Mantovani, J. R., Rezende, A. V., \& Florentino, L. A. (2020B). Bacterial strains decrease solubility of potassium in the soil. Bioscience Journal, 36 (5), 1577-1582.

Paula, A. C., Melo, K. M., Silva, A. M., Ferreira, D. A., Monte, F. J. Q., Santiago, G. M. P., Lemos, T. L. G., Braz, R., Militão, G. C. G., Silva, P. B. N. \& Silva, T. G. (2016). Constituintes Químicos e Atividade Citotóxica de Cnidoscolus phyllacanthus. Revista Virtual de Química, 8 (1), $231-141$.

Polyak, Y. M. \& Sukcharevich, V. I. (2019). Allelopathic Interactions between Plants and Microorganisms in Soil Ecosystems. Biology Bulletin Reviews, 9 (6), 562-574.

Silva, E. S., Santos, C. A., Dias, K. S., Souza, M. A., Santos, A. F. \& Pavão, J. M. S. J. (2018). Cenário das pesquisas sobre alelopatia no Brasil e seu potencial como estratégia na diminuição da utilização de pesticidas que provocam poluição ambiental: uma revisão integrativa. Diversitas Journal, 3 (2), $442-454$.

Silva, M. A. D., Silva, J. N., Alves, R. M., Gonçalves, E. P. \&Viana, J. S. (2021). Allelopathy of Caatinga species. Research, Society and Development, 10 (4), e57610414328

Silva, K. P., Silva, G. O. A., Oliveira, T. E., Rezende, A. V. \& Florentino, L. A. (2019). Promoção de crescimento de capim Mombaça por bactérias diazotróficas. Pesquisa Agropecuária Tropical, 49, e56732.

Terra, A. B. C., Souza, F. R. C., Mantovani, J. R., Rezende, A. V. \& Florentino, L. A. (2019). Physiological characterization of diazotrophic bacteria isolated from Brachiaria brizantha rhizosphere. Revista Caatinga, 32 (3), 658-666.

Toledo, C. N., Dias, N. C. S., Florentino, L. A. \& Rezende, A. V. (2019). Compostos alelopáticos em Brachiaria spp. e sua interação com bactérias diazotróficas associativas. Nucleus Animalium, 11 (2), 1-16.

Witter, A. P. W., Nohatto, M. A. Rosa, E. F. F.; Kaseker, J. F. \& Bereta, S. F. (2021). Uso de inoculantes para redução do efeito alelopático da canola sobre a cultura da soja. Acta Iguazu, 10 (1), 113-121. 